\title{
Contributions of Microscopy to Advanced Industrial Materials and Processing
}

\author{
S. Dionne*, G.J.C. Carpenter*, G. A. Botton*, T. Malis*, and M. W. Phaneuf** \\ *CANMET-Materials Technology Laboratory, 568 Booth St., Ottawa, Canada K1A 0G1 \\ **Fibics Inc., 556 Booth St., Ottawa, Canada K1A 0G1
}

The Canadian federal Materials Technology Laboratory supplies microstructure characterization services to projects involving a broad range of materials and product forms. TEM usage in industrial issues is often contingent on a preliminary evaluation suggesting that data is needed on a finer scale. Overviews of the microstructure are obtained via optical microscopy or SEM imaging so as to decide upon the key regions for TEM analysis. Recently, our TEM capability was augmented greatly by usage of focused ion beam (FIB) methodologies provided by a private sector partner. In this paper, we hope to convey a generic sense of industrial usage of analytical TEM via our own experience with characterization of advanced coatings and materials. Additional examples are presented in a recent compilation [1].

The hot-dipped iron-zinc coating known as galvanneal has seen expanded use for automotive applications. The in-service properties of galvanneal are very sensitive to the coating microstructure. TEM characterization of galvannealed steel is challenging since the coating is relatively thin and is sensitive to both beam heating and beam damage. Several phases in the Al-FeZn system may be present which have overlapping composition limits and extensive solid solubility. A sequential use of SEM, FIB and analytical TEM has provided the most comprehensive set of results for galvanized and galvannealed steels. FIB images were useful for observing the relationship between the coating phases and substrate grains (FIG. 1) and for the selection, in-situ, of the best regions for TEM specimen preparation using the FIB lift-out technique. Elemental mapping of the uniform thickness cross-sections revealed unexpected features such as the diffusion of $\mathrm{Zn}$ along a ferrite grain boundary (FIG. 2). CBED and EDXS point analyses allowed phase determinations and higher resolution measurements on selected regions. Finally, plan view specimens prepared in the form of extraction replicas using a selective etching technique were invaluable for identifying the coating phases without the problem of $\mathrm{Zn}$-depletion that sometimes accompanied ion preparation (FIG. 3).

Metal-matrix composites (MMCs) offer potential for improved specific properties in comparison with metal alloys. The strength and cleanliness of the reinforcement/matrix interfaces play a major role in determining the failure mode of MMCs. The effectiveness of fabrication procedures for $\mathrm{Mg}$ based composites by the squeeze-casting route were continually evaluated using SEM and TEM. Coarse reaction products were detected in the SEM, while small interface features were best studied using analytical TEM. STEM Dark Field imaging proved to be a particularly effective means for quickly assessing the degree of $\mathrm{MgO}$ formation in a particular melt, as shown in FIG. 4. Ultimately, a proprietary binder was produced that, together with careful control of the processing parameters, virtually eliminated the undesired interface reactions. 
References

[1] T. Malis et al., Contributions of Microscopy to Advanced Industrial Materials and Processing, to be published in Industrial Electron Microscopy, ed. Z. R. Li, Marcel Dekker Inc., 2002.

[2] We thank Dr. Frank Goodwin of ILZRO for financial assistance and provision of material as well as Mr. M. Charest and Dr. J. Lo of MTL for valuable contributions of expertise and specimens.

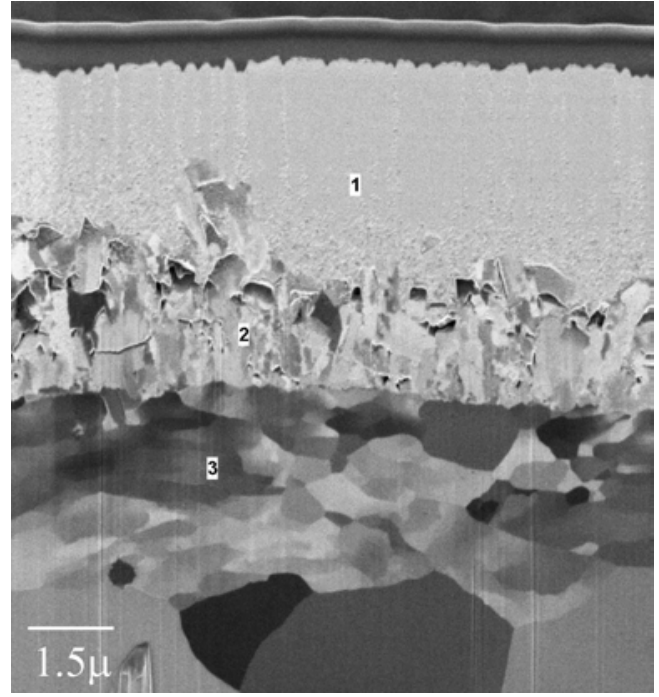

FIG. 1. FIB SE image of a cross-section of galvannealed steel showing (1) $\mathrm{Zn}$ overlay, (2) $\zeta$ and $\delta$ crystals resulting from the reaction and (3) steel substrate.

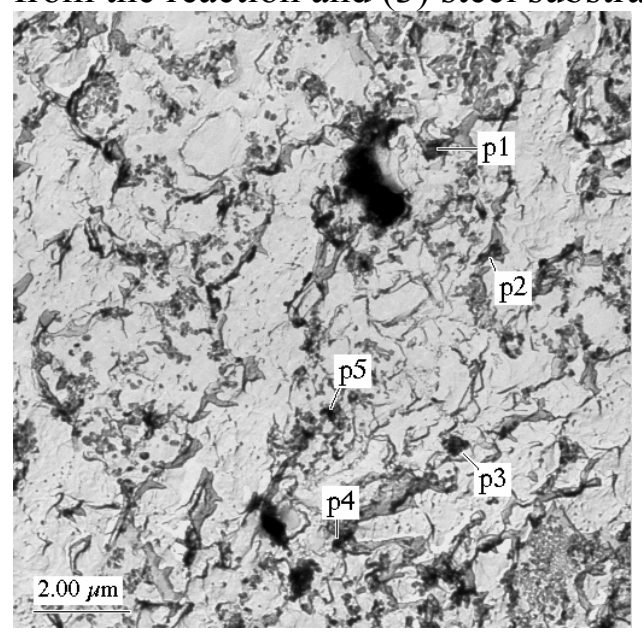

FIG. 3. Cluster of extracted inhibition layer particles on a replica of partially galvannealed Ti-IF steel. Particle 5 was identified as $\mathrm{Fe}_{2} \mathrm{Al}_{5}$ with the zone axis [01 $\overline{1}]$ using CBED.

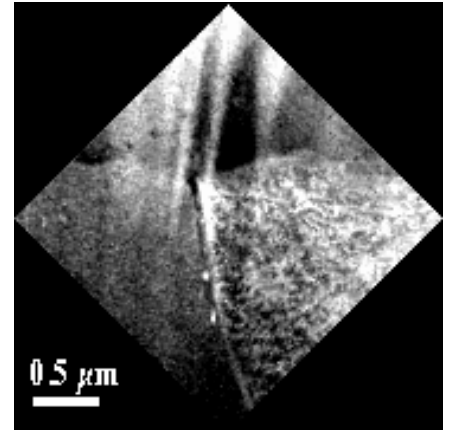

Dark Field image.

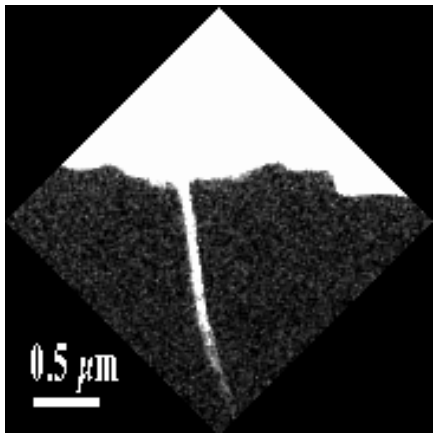

Zinc map.
FIG. 2. STEM-DF image and zinc elemental map of a FIB lift-out specimen of galvanized low carbon steel showing zinc diffusion along an emerging ferrite grain boundary.

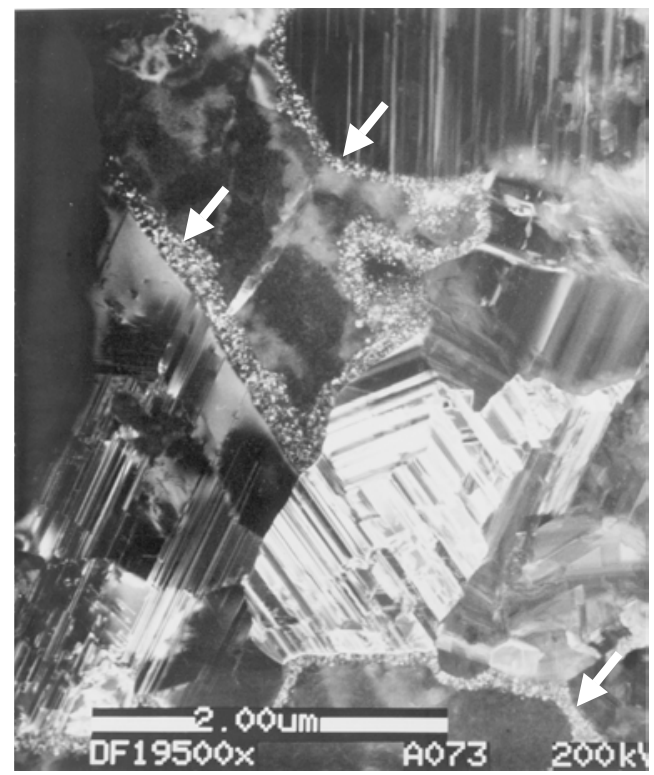

FIG. 4. STEM-DF image of a Mg-based squeeze cast composite, showing the strong visibility of the $\mathrm{MgO}$ films (arrowed) in this imaging mode. 